\title{
Pulse oximetry-based capillary refilling evaluation predicts postoperative outcomes in liver transplantation: a prospective observational cohort study
}

Miyuki Yamamoto ${ }^{1}$, Kent Doi ${ }^{{ }^{*}}$ (D, Naoki Hayase ${ }^{1}$, Toshifumi Asada ${ }^{1}$, Nobuhisa Akamatsu², Junichi Kaneko², Kiyoshi Hasegawa ${ }^{2}$ and Naoto Morimura ${ }^{1}$

\begin{abstract}
Background: Capillary refill time (CRT) is a non-invasive technique to evaluate tissue perfusion, and quantitative CRT (Q-CRT) adapted to pulse oximetry was developed with patients with sepsis and compared to blood lactate and sepsis scores. In post liver transplantation, large amounts of fluid administration are necessary for maintaining tissue perfusion to grafted liver against intravascular hypovolemia. This study aimed to evaluate whether Q-CRT can predict poor outcomes by detecting peripheral tissue perfusion abnormality in patients with liver transplantations who were treated with massive fluid administration.

Methods: In this single-center prospective cohort study, we enrolled adult patients with liver transplantations between June 2018 and July 2019. Measurement of Q-CRT was conducted at intensive care units (ICU) admission and postoperative day 1 (POD1).

Results: A total of 33 patients with liver transplantations were enrolled. Significant correlations of Q-CRT and $\Delta A_{b}$, a tissue oxygen delivery parameter calculated by pulse oximetry data, at ICU admission with the postoperative outcomes such as length of ICU and hospital stay and total amount of ascitic fluid discharge were observed. Quantitative CRT and $\triangle A_{b}$ at ICU admission were significantly associated with these postoperative outcomes, even after adjusting preoperative and operative factors (MELD score and bleeding volume, respectively). However, quantitative CRT and $\triangle A_{b}$ at POD1 and changes from ICU admission to POD1 failed to show significant associations.

Conclusions: Q-CRT values were significantly associated with postoperative outcomes in liver transplantation. Although the mechanisms of this association need to be clarified further, Q-CRT may enable identification of highrisk patients that need intensive postoperative managements.
\end{abstract}

Keywords: Capillary refill time, Non-invasive, Tissue perfusion, Liver transplantation, Perioperative management, Pulse oximeter

\footnotetext{
*Correspondence: kdoi-tky@umin.ac.jp

'Department of Acute Medicine, The University of Tokyo, 7-3-1 Hongo, Bunkyo-ku, Tokyo 113-0033, Japan

Full list of author information is available at the end of the article
}

(C) The Author(s). 2020 Open Access This article is licensed under a Creative Commons Attribution 4.0 International License, which permits use, sharing, adaptation, distribution and reproduction in any medium or format, as long as you give appropriate credit to the original author(s) and the source, provide a link to the Creative Commons licence, and indicate if changes were made. The images or other third party material in this article are included in the article's Creative Commons licence, unless indicated otherwise in a credit line to the material. If material is not included in the article's Creative Commons licence and your intended use is not permitted by statutory regulation or exceeds the permitted use, you will need to obtain permission directly from the copyright holder. To view a copy of this licence, visit http://creativecommons.org/licenses/by/4.0/ The Creative Commons Public Domain Dedication waiver (http://creativecommons.org/publicdomain/zero/1.0/) applies to the data made available in this article, unless otherwise stated in a credit line to the data. 


\section{Background}

Monitoring tissue perfusion is important for the management of critically ill patients in intensive care units (ICUs), since insufficient oxygen delivery to peripheral tissues is strongly associated with organ dysfunction in many conditions such as sepsis and postsurgical organ failure [1-3]. In contrast to hemodynamic parameters that can be measured by pulmonary artery catheters and ultrasound techniques, only few measurements that can evaluate tissue perfusion are clinically available. Sublingual videomicroscopy can measure tissue perfusion in a real-time manner; however, these devices are expensive and not easily applied to clinical use $[4,5]$.

Capillary refill time (CRT) is a simple, fast, and noninvasive method for evaluating tissue perfusion. This method has been used in the field of disaster medicine as a triage tool $[6,7]$. A recent clinical trial demonstrated that inclusion of CRT measurement in septic shock management at ICUs can reduce mortality risk [8]. Although CRT may be affected by inter-examiner differences $[9,10]$, a recently developed device can measure CRT quantitatively by using a pulse oximeter [11]. Our recent validation studies discovered a significant correlation between venous blood lactate levels and quantitative CRT (Q-CRT), as measured via the pulse oximeter-based device, in a cohort of ICU patients and emergency department (ED) patients $[11,12]$. Q-CRT in 23 ICU patients was demonstrated to be statistically correlated with lactate levels (Spearman's rank correlation coefficient, $0.681 ; p<0.001$ ) [11]. In addition to Q-CRT, we developed the delta $A_{b}\left(\Delta A_{b}\right)$ measure, which is based on the amount of light absorbed into finger tissue and blood flow by subtracting the light quantity input value from the output value. $\Delta \mathrm{A}_{\mathrm{b}}$ is assumed to reflect overall peripheral oxygen delivery and integrates blood flow, oxygenation, and hemoglobin concentration [12].

Liver transplantation is widely performed for endstage liver failure. Advances in surgical procedures and immunosuppressive therapy significantly improved the outcomes of liver transplantation [13-15]. Postsurgical management of liver transplantation is of great importance in critical care medicine, because large amounts of fluid administration is frequently necessary to maintain intravascular volume and adequate portal vein blood flow to the grafted liver. Although the blood lactate level is utilized to evaluate oxygen delivery to peripheral tissues in managing septic shock, alterations in lactate levels are influenced by factors other than peripheral hypoperfusion, including liver dysfunction [16, 17]. Several studies reported on the benefit of lactate reduction as a clinical parameter for monitoring early graft function following liver transplantation [18-20]. So, far, no study has assessed the clinical application of Q-CRT in liver transplantation, although we previously evaluated Q-
CRT in septic patients. This prospective observational study was performed in order to examine whether QCRT and $\triangle \mathrm{A}_{\mathrm{b}}$ values measured following liver transplantation are associated with postoperative outcomes.

\section{Methods}

\section{Patient population and study design}

In this single-center prospective cohort study, we enrolled patients who received liver transplantation and who were admitted to the ICU of the University of Tokyo Hospital between June 2018 and July 2019. Orthotopic liver transplantation followed the standardized procedure in all cases with the living donor partial liver or the deceased donor whole liver. Intraoperative porto-caval shunt was never created in this series. All 18 years old or older patients were eligible, and patients who did not agree to participate and/or who demonstrated missing data were excluded. The study protocol adhered to the Declaration of Helsinki and was approved by the institutional review board of the University of Tokyo. Informed consent was obtained from each participant.

Regarding postoperative management, chest and abdominal radiographs, and abdominal and cardiac ultrasonography examinations were performed at least daily until POD14. Treatment with diuretics such as furosemide, spironolactone, and human atrial natriuretic peptide, albumin preparations, and vasopressors was administered at the physician's clinical discretion.

\section{Q-CRT and $\Delta \mathrm{A}_{\mathrm{b}}$ measurements}

Measurements of $\mathrm{Q}-\mathrm{CRT}$ and $\triangle \mathrm{A}_{\mathrm{b}}$ were performed based on the principle of pulse oximetry. The measurement principle and device wearing method are described in detail, in our previous report [12]. Briefly, transmitted light quantity was measured by a pulse oximeter (OLV3100, Nihon Kohden Corporation, Tokyo, Japan) equipped with an $\mathrm{SpO}_{2}$ sensor. This device has not been approved for clinical use yet. Mechanical pressure with $500 \mathrm{mmHg}$ lasting for $5 \mathrm{~s}$ was applied to the patient's nail bed of the index or middle finger. The values of $\mathrm{Q}$ CRT and $\triangle \mathrm{A}_{\mathrm{b}}$ were determined as the average of five measurements. The ICU room temperature was kept between $24^{\circ} \mathrm{C}$ and $26^{\circ} \mathrm{C}$, and the room lighting was on during the measurement.

Quantitative CRT was defined as the time in seconds from the release of the pressure to the time when the blood flow reached $90 \%$ of the original flow, which was measured for $5 \mathrm{~s}$ at the beginning of the test before applying pressure. Transmitted light quantity measured by a pulse oximeter is equivalent to the amount of light absorbed into finger tissue and blood flow and equivalent to the amount of light absorbed into finger tissue only under compression. The quantity of light dimmed 
by blood only defines the $\Delta \mathrm{A}_{\mathrm{b}}$ (delta $\mathrm{A}_{\mathrm{b}}$ ), which is the difference between the quantity of light dimmed under infrared light and that dimmed under red light. In short, $\Delta \mathrm{A}_{\mathrm{b}}$ can be determined by oxidized hemoglobin levels (oxygen saturation), hemoglobin concentration, and tissue thickness with blood flow (peripheral circulation blood volume) [12].

\section{Data collection}

The following patient characteristics and clinical data were collected from the medical records: age, sex, body temperature, height, weight (before transplantation), amount of ascites, and underlying liver disease. Preoperative model for end-stage liver disease (MELD) and Child-Pugh scores were calculated. Donor information such as age, sex, weight, and graft size were collected. The following clinical variables were evaluated as intraoperative factors: operative time, bleeding volume, intraoperative fluid balance, anhepatic time, and ischemic time of graft.

At ICU admission after liver transplantation surgery, Q-CRT and $\triangle \mathrm{A}_{\mathrm{b}}$ measurements were performed. Other clinical parameters, including vital signs, usage of vasoactive agents, and measurements of central venous pressure (CVP), were also obtained. Additionally, laboratory data recorded at ICU admission included blood lactate, hemoglobin $(\mathrm{Hb})$, total bilirubin, and prothrombin time international normalized ratio (PT-INR). We performed hepatic blood flow assessment twice daily, determining the amount of fluid volume based on the results of echocardiography and CVP monitoring. Q-CRT, $\Delta \mathrm{A}_{\mathrm{b}}$, and blood lactate were also measured at postoperative day 1 (POD1).

Daily ascites was defined as the total amount of ascites through the abdominal tube and exudate. Abdominal drain tubes were routinely inserted near the surface of the donor graft, behind the graft hilum, and into the rectovesicular (Douglas) pouch. In cases with simultaneous splenectomy, an additional drain tube was placed into the left sub-phrenic cavity. In patients with pleural effusion, drainage was performed by the placement of thoracic catheter. The total amount of discharge was recorded, including pleural effusion.

\section{Sample size estimation}

As a small pilot study, we compared the Q-CRT at ICU admission between five liver transplant patients with massive ascites (ascites volume $>1000 \mathrm{ml} /$ day on POD 14) and five liver transplant patients with non-massive ascites. The estimated difference of the mean and standard deviation were 0.55 and 0.41 , respectively, using logtransformed data. On this basis, the sample size was calculated as being 10 patients with massive ascites and 10 patients with non-massive ascites, assuming a type I error rate of 0.05 , a power of 0.8 , an anticipated effect size $\mathrm{d}=$ difference of means $/$ standard deviation $=1.34$.

\section{Statistical analysis}

Continuous variables were presented as medians with interquartile ranges, and categorical variables were presented as percentages. Categorical data were compared by the chi-square or Fisher's exact test, while continuous data were compared by Student's $t$ test or Wilcoxon's rank-sum test. Correlations between variables were analyzed using Spearman's rank correlation. All continuous parameters with a skewed distribution were entered into these models as log-transformed variables using the natural logarithm to the base e. A multivariable logistic regression model was used to evaluate the independent contribution of Q-CRT or $\Delta \mathrm{A}_{\mathrm{b}}$ to the outcomes by adjusting predefined preoperative (MELD score) and operative (blood loss during surgery) factors. The cut-off point was determined using receiver operating characteristic (ROC) analysis with Youden-index. All statistical analyses and calculations were performed using the $\mathrm{JMP}^{\circ}$ Pro software (version 14.2.0; SAS Institute, Cary, $\mathrm{NC}$ ). A two-tailed probability (p) value $<0.05$ was considered statistically significant for all tests.

\section{Results}

\section{Patient characteristics}

We enrolled a total of 33 patients with liver transplantations. Table 1 shows characteristics and clinical parameters at ICU admission after surgery. Hyperlactemia and hyperbilirubinemia were observed. Additional file 1 summarized the preoperative baseline characteristics, graft conditions, surgery-related factors of the study population, and other clinical parameters at ICU admission after surgery.

\section{Q-CRT and $\Delta \mathrm{A}_{\mathrm{b}}$ at ICU admission}

Figure $1 \mathrm{a}$ and $\mathrm{b}$ show the values of $\mathrm{Q}-\mathrm{CRT}$ and $\Delta \mathrm{A}_{\mathrm{b}}$ at ICU admission, respectively. Significant correlations were observed for Q-CRT and $\triangle \mathrm{A}_{\mathrm{b}}$ with regard to mean arterial pressure (MAP) (Fig. 1c), portal vein (PV) velocity (Fig. 1d), while no significant correlation of Q-CRT or $\Delta \mathrm{A}_{\mathrm{b}}$ with blood lactate, heart rate (HR), CVP, hemoglobin, and hepatic artery (HA) velocity was observed (Additional file 2).

\section{Postoperative data}

Four patients developed early allograft dysfunction (EAD) [21], and one patient had graft failure 6 months following transplantation. The Q-CRT and $\triangle \mathrm{A}_{\mathrm{b}}$ values showed no difference between the EAD and the nonEAD patients (data not shown). One year later, all patients were still alive. 
Table 1 Characteristics and clinical parameters at ICU admission

\begin{tabular}{lll}
\hline Variables & & \\
\hline Recipient characteristics & age (years) & $52(43-60)$ \\
& male sex & $17(51.5 \%)$ \\
& body weight $(\mathrm{kg})$ & $57.7(53.3-68.0)$ \\
& Child-Pugh score & $10(8-12)$ \\
& MELD score & $15(10-19)$ \\
& perioperative ascites & $13(39.4 \%)$ \\
Clinical parameters at & body temperature $\left({ }^{\circ} \mathrm{C}\right)$ & $37.2(36.6-37.6)$ \\
ICU admission & heart rate (/min) & $101(95-109)$ \\
& mean arterial & $73(66-83)$ \\
& pressure (mmHg) & \\
& usage of vasoactive agents & $11(33.3 \%)$ \\
& lactate (mg/dL) & $5.4(2.9-9.1)$ \\
& total bilirubin (mg/dL) & $3.1(2.2-6.0)$ \\
& PT-INR & $1.37(1.26-1.50)$ \\
& portal venous flow & $54.8(37.5-82.1)$ \\
& velocity (cm/sec)
\end{tabular}

Summary statistics are reported as No. (\%), medians (lower and upper quartiles)

MELD the model for end-stage liver disease, PT-INR prothrombin time international normalized ratio

The median lengths of ICU and hospital stay were 13 days (IQR 9-18) and 47 days (IQR 30-71), respectively. With regard to the length of ICU stay and post-surgery hospitalization, significant correlations were observed for both Q-CRT and $\triangle \mathrm{A}_{\mathrm{b}}$ (Fig. 2a-b). The median total ascitic discharge at 7 and 14 days was $20.6 \mathrm{~L}$ (IQR 10.336.9) and 45.4 L (IQR 21.9-72.7), respectively. Both Q$\mathrm{CRT}$ and $\triangle \mathrm{A}_{\mathrm{b}}$ showed significant correlations with the total amount of ascites discharge 7 and 14 days after the surgery (Fig. 2c-d). Portal vein, not hepatic artery and vein, blood flow measured just after the surgery demonstrated significant correlation with ascites discharge 7 and 14 days after surgery (Additional file 3).

Based on the preoperative ascites volume, the patients were divided into three groups (a no ascites group, a non-massive ascites group: $1-999 \mathrm{ml}$, and a massive ascites group: $>1000 \mathrm{ml}$ ). Patients who had preoperative massive ascites displayed the largest amount of postoperative ascites (Additional file 4). The enrolled patients were divided into two groups using a cutoff value of the total amount of ascitic discharge of $1000 \mathrm{~mL} /$ day at POD14, based on the diagnostic criteria for small-forsize syndrome and previous reports [22-24] (Table 2 and Additional file 5). The group exhibiting more ascitic discharge showed significantly longer Q-CRT and lower $\Delta \mathrm{A}_{\mathrm{b}}$ values at ICU admission. The Q-CRT and $\Delta \mathrm{A}_{\mathrm{b}}$ cutoff values, the area under the curve (AUC), and the 95\% confidence interval $(\mathrm{CI})$ for each outcome in patients with massive ascites are shown (Additional file 6). Multiple regression analysis demonstrated that Q-CRT and
$\Delta A_{b}$ at ICU admission were significantly associated with the length of ICU stay, length of post-surgery hospitalization, and total amount of ascitic discharge for 14 days after surgery, even after adjusting confounding factors of preoperative MELD score and intraoperative blood loss (Table 3 ).

\section{Serial measurements of Q-CRT and $\Delta A_{b}$}

Quantitative CRT and $\Delta \mathrm{A}_{\mathrm{b}}$ were measured at POD1. Due to missing data, three patients were excluded from the analysis. No significant correlations for Q-CRT at POD1 were observed between these measurements and length of ICU stay, post-surgery hospitalization, or total amount of ascites for 14 days after surgery. $\Delta A_{b}$ at POD1 did not significantly correlate with length of ICU stay or post-surgery hospitalization but with the total amount of ascitic discharge for 14days after surgery (Fig. 3). The absolute changes in Q-CRT from ICU admission to POD1 failed to show any significant association with these outcomes. The absolute changes in $\Delta \mathrm{A}_{\mathrm{b}}$ from ICU admission to POD1 did not show any significant correlation with length of ICU stay or number of days of hospitalization after surgery but with the total amount of ascitic discharge for 14 days after surgery (Additional file 7). We also evaluated a possible correlation between Q-CRT and $\triangle \mathrm{A}_{\mathrm{b}}$ and the change of MELD score before and after the transplantation surgery. No significant correlation was found in perioperative changes of the MELD score with Q-CRT and $\triangle \mathrm{A}_{\mathrm{b}}$ (data not shown). Maximum lactate values during surgery, ICU admission, $12 \mathrm{~h}$ after admission, and POD1 are shown in Fig. 4a. No significant correlation between the absolute changes in Q-CRT and $\triangle \mathrm{A}_{\mathrm{b}}$ from ICU admission to POD1 with lactate clearance was observed (Fig. 4b-c). No significant correlation was observed between the lactate clearance and 14 days total discharge, length of ICU stay, and length of hospitalization after surgery (data not shown). The enrolled patients were divided into two groups by the change in Q-CRT and $\triangle \mathrm{A}_{\mathrm{b}}$ from ICU admission to POD1, but no significant difference in the outcomes between the two groups was observed (Table 4).

\section{Discussion}

This study evaluated tissue perfusion in patients with postoperative liver transplantations by a quantitative CRT method using a pulse oximeter. Significant associations between Q-CRT and length of ICU and hospital stays and large postoperative ascitic discharge were observed. The newly developed parameter of $\Delta A_{b}$, which is expected to reflect the total oxygen delivery to the peripheral tissues, was also significantly associated with these outcomes. These observations suggest that the newly developed Q-CRT method might be helpful to 

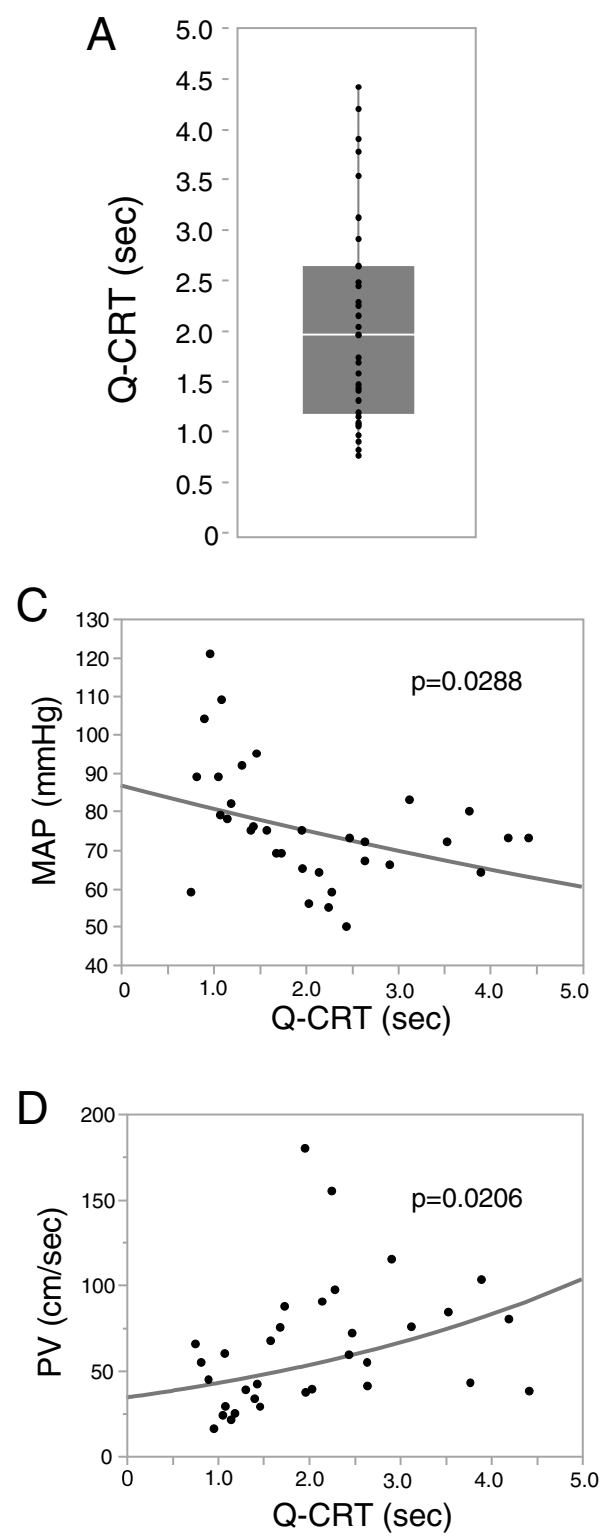
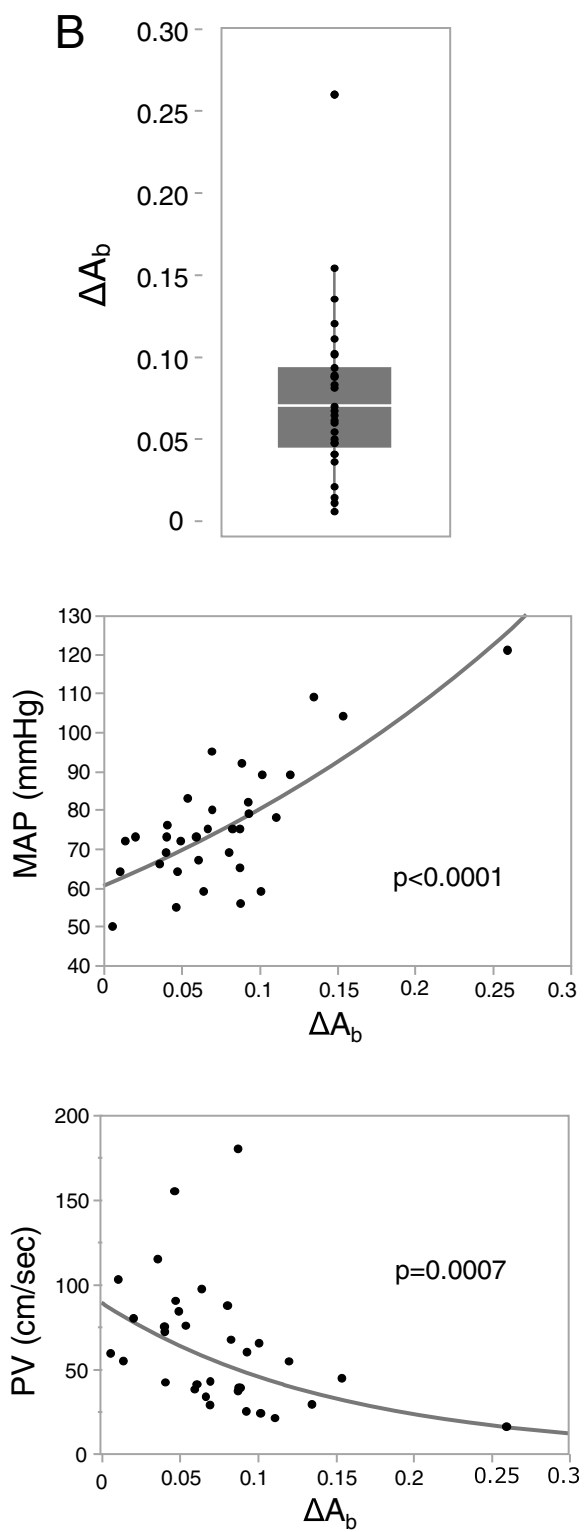

Fig. 1 Quantitative capillary refill time and $\Delta A_{b}$ at ICU admission. Distributions of Q-CRT (a) and $\triangle A_{b}$ (b) measured at ICU admission. Box plots show the median (center line), the 25th and 75th percentiles, and the range. Correlations of Q-CRT and $\Delta \mathrm{A}_{b}$ with mean arterial pressure (MAP) (c) and portal venous velocity (PV) (d). Measures observed at similar time points $(N=33)$. The $p$ value is indicated in each graph

detect tissue perfusion abnormalities influencing organ function of the grafted liver in postoperative period. This suggestion may be supported by the observation that Q$\mathrm{CRT}$ and $\Delta \mathrm{A}_{\mathrm{b}}$ were significantly correlated with portal and hepatic vein blood flow rate measured using ultrasound. Q-CRT technique is expected to be accomplished more easily than blood flow measurement using ultrasound. It should be addressed that a single measurement of peripheral tissue perfusion was associated with the outcomes; however, many related mechanisms are presumed to be involved in these significant associations. This study suggested that a simple evaluation method of
Q-CRT may be useful for clinical management in liver transplantation patients, and further evaluation is absolutely necessary.

CRT is a simple and non-invasive test used to assess peripheral perfusion at the bedside. Although CRT can be used without any equipment, intra-examiner differences and poor reproducibility, even by the same observers, were reported $[9,10,25]$. CRT can be affected by the surrounding environment such as temperature and lightning [10, 26], unifying measurement condition is an important point. To overcome this problem, several investigations were conducted. Kawaguchi and 

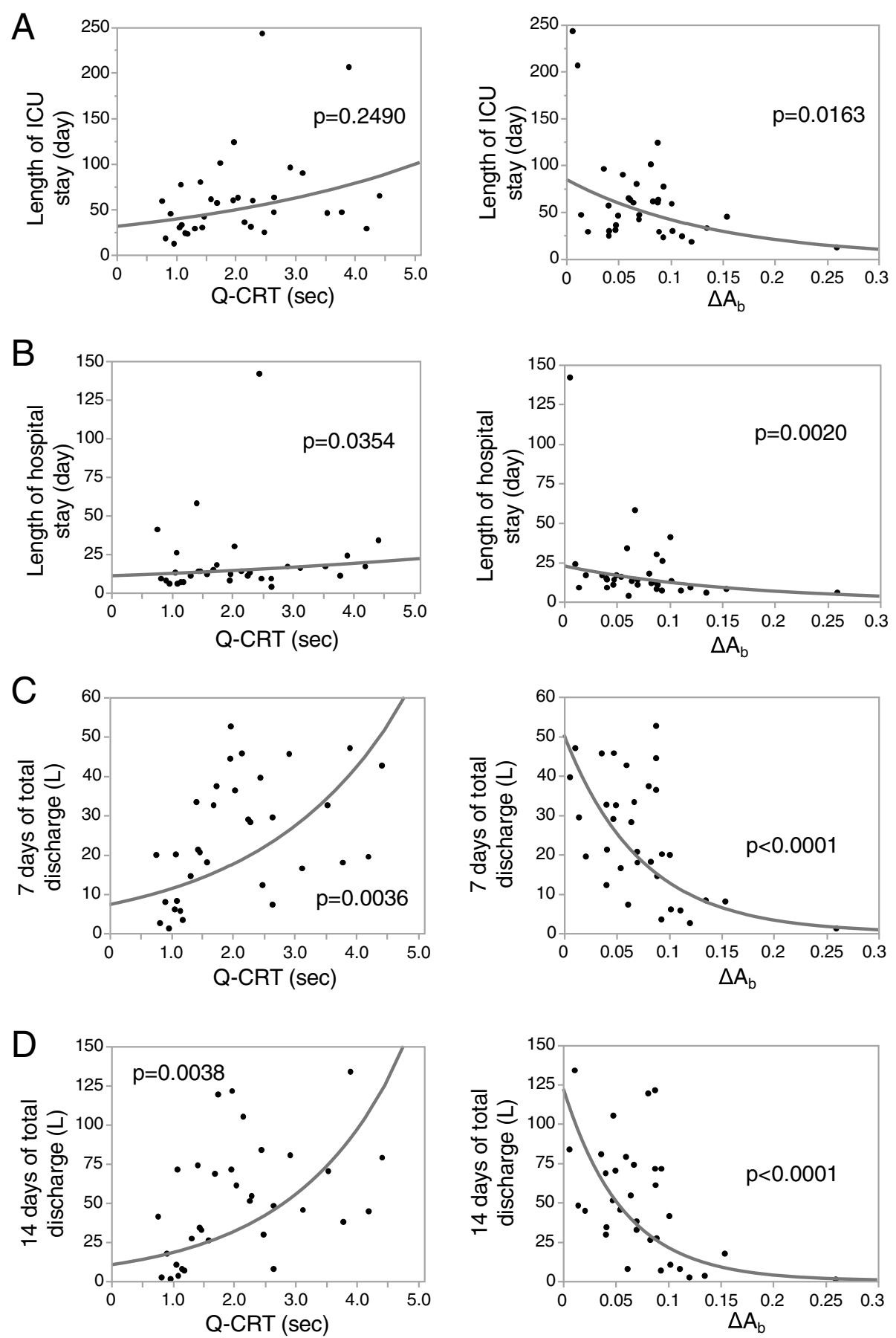

Fig. 2 Correlations of Quantitative capillary refill time, $\Delta A_{b}$ with the outcomes. Correlations with length of post-surgery ICU stay (a), hospital stay (b), the total amount of discharge for 7 days (c) and 14 days (d) after the surgery are shown $(N=33)$. The $p$ value is indicated in each graph

colleagues developed a device that can be adjusted for pressing strength and time using an electric actuator and strength and color sensors [27, 28]. Shinozaki and colleagues used fingernail video recording and image analysis software for calculating CRT [29]. We developed a new device that can measure CRT quantitatively by using the pulse oximeter. This new device automatically compresses the finger with a constant pressure of 500 $\mathrm{mmHg}[11]$ and was applied to patients with suspected sepsis at ED [30]. Another study also evaluated quantitative CRT using a pulse oximeter in ED patients [31]. Our device demonstrates the advantage of measuring not only Q-CRT but $\triangle \mathrm{A}_{\mathrm{b}}$, an index of integrated peripheral oxygen delivery status, because pulse oximetry 
Table 2 Comparison of the non-massive ascites group with the massive ascites group

\begin{tabular}{|c|c|c|c|c|}
\hline & & $\begin{array}{l}\text { Non-massive ascites } \\
\text { group }(N=10)\end{array}$ & $\begin{array}{l}\text { Massive ascites } \\
\text { group }(N=23)\end{array}$ & $p$ value \\
\hline \multirow[t]{6}{*}{ Recipient characteristics } & age (years) & $45(34-58)$ & $54(47-62)$ & 0.1580 \\
\hline & male sex & $5(50 \%)$ & $12(36.4 \%)$ & 0.9086 \\
\hline & body weight (kg) & $67.5(57.2-71.8)$ & $54.6(52.0-67.0)$ & 0.0525 \\
\hline & Child-Pugh score & $8(6-10)$ & $10(9-12)$ & 0.0089 \\
\hline & MELD score & $13(8-16)$ & $16(10-24)$ & 0.0593 \\
\hline & preoperative ascites & $1(10 \%)$ & $12(36.4 \%)$ & 0.0227 \\
\hline \multirow[t]{10}{*}{ Clinical parameters at ICU admission } & body temperature $\left({ }^{\circ} \mathrm{C}\right)$ & $37.5(37.2-37.8)$ & $37.0(36.5-37.5)$ & 0.0544 \\
\hline & heart rate (/min) & $98(93-102)$ & $102(95-116)$ & 0.1580 \\
\hline & mean arterial pressure $(\mathrm{mmHg})$ & $86(76-99)$ & $72(64-75)$ & 0.0025 \\
\hline & usage of vasoactive agents & $1(10 \%)$ & $10(43.5 \%)$ & 0.0608 \\
\hline & lactate (mmol/L) & $4.7(1.9-9.0)$ & $5.4(3.2-9.5)$ & 0.4929 \\
\hline & total bilirubin (mg/dL) & $2.4(1.1-3.8)$ & $3.2(2.4-6.7)$ & 0.0848 \\
\hline & PT-INR & $1.32(1.22-1.43)$ & $1.37(1.27-1.50)$ & 0.4804 \\
\hline & Q-CRT (sec) & $1.17(1.03-1.49)$ & $2.25(1.68-3.12)$ & 0.0061 \\
\hline & $\Delta \mathrm{A}_{\mathrm{b}}$ & $0.097(0.067-0.124)$ & $0.060(0.040-0.088)$ & 0.0109 \\
\hline & early allograft dysfunction & $1(10 \%)$ & $3(13 \%)$ & 0.8055 \\
\hline \multirow[t]{4}{*}{ Outcomes } & Length of ICU stay (day) & $8(6-13)$ & $16(11-26)$ & 0.0025 \\
\hline & Length of hospital stay (day) & $30(22-47)$ & $60(45-90)$ & 0.0040 \\
\hline & 7 days total discharge $(\mathrm{L})$ & $6.7(3.3-18.7)$ & $32.6(19.5-42.6)$ & 0.0003 \\
\hline & 14 days total discharge $(\mathrm{L})$ & $7.8(3.3-27.8)$ & $68.7(44.6-80.5)$ & $<0.0001$ \\
\hline
\end{tabular}

Summary statistics are reported as No. (\%), medians (lower and upper quartiles)

MELD model for end-stage liver disease, PT-INR prothrombin time international normalized ratio

enables the measurement of transmitted light quantities under red and infrared light [12]. In this study, both QCRT and $\Delta \mathrm{A}_{\mathrm{b}}$ showed significant associations with post liver transplantation outcomes. Further investigation is necessary to identify which of these parameters would serve the patients better in other specific situations such as septic shock, post-cardiac surgery, and severe trauma.

Liver transplantation is expected to reduce portal hypertension and associated ascites transudation. However, massive ascites is one of the most frequent complications and poor prognostic factors in liver transplantation [32-34]. Several clinical risk factors for considerable amounts of postoperative ascites include preoperative MELD score, large blood loss volume, and small-sized grafts [35-37]. Our previous study reported that $48 \%$ of patients receiving living donor liver transplants developed massive postoperative ascites $(>1000$ $\mathrm{mL} /$ day at POD14), and it also reported that preoperative ascites, intraoperative blood loss, and duration of anhepatic phase were associated with considerable

Table 3 Multiple regression analysis of Q-CRT and $\Delta A_{b}$ at ICU admission

\begin{tabular}{|c|c|c|c|c|c|c|}
\hline \multirow[b]{2}{*}{ Variable } & \multirow{2}{*}{$\begin{array}{l}\text { ICU Stay } \\
\text { odds ratio }(95 \% \mathrm{Cl})\end{array}$} & \multirow[b]{2}{*}{$p$ value } & \multirow{2}{*}{$\begin{array}{l}\text { Hospital Stay } \\
\text { odds ratio }(95 \% \mathrm{Cl})\end{array}$} & \multirow[b]{2}{*}{$p$ value } & \multicolumn{2}{|l|}{ Ascitic discharge } \\
\hline & & & & & odds ratio $(95 \% \mathrm{Cl})$ & $p$ value \\
\hline MELD score & $0.935(0.817-1.052)$ & 0.2660 & $0.870(0.759-0.996)$ & 0.0222 & $0.770(0.588-1.008)$ & 0.0075 \\
\hline blood loss & $1.000(0.999-1.000)$ & 0.3418 & 1.000 (0.999-1.000) & 0.0753 & 1.000 (0.999-1.000) & 0.8759 \\
\hline \multirow[t]{2}{*}{ Q-CRT } & $0.538(0.212-1.182)$ & 0.1256 & $0.304(0.106-0.871)$ & 0.0084 & $0.056(0.005-0.626)$ & 0.0002 \\
\hline & & 0.0835 & & 0.0274 & & 0.0002 \\
\hline MELD score & $0.936(0.828-1.057)$ & 0.2638 & $0.896(0.786-1.022)$ & 0.0649 & $0.823(0.655-1.033)$ & 0.0340 \\
\hline blood loss & $1.000(0.999-1.000)$ & 0.3789 & $1.000(0.999-1.000)$ & 0.1649 & $1.000(0.999-1.000)$ & 0.9656 \\
\hline \multirow[t]{2}{*}{$\Delta A_{b}$} & $2.51 e^{12}\left(2.364-2.67 e^{24}\right)$ & 0.0106 & $4.17 e^{9}\left(0.614-2.83 e^{10}\right)$ & 0.0190 & $4.69 e^{13}\left(5.512-3.99 e^{26}\right)$ & 0.0048 \\
\hline & & 0.0126 & & 0.0525 & & 0.003 \\
\hline
\end{tabular}



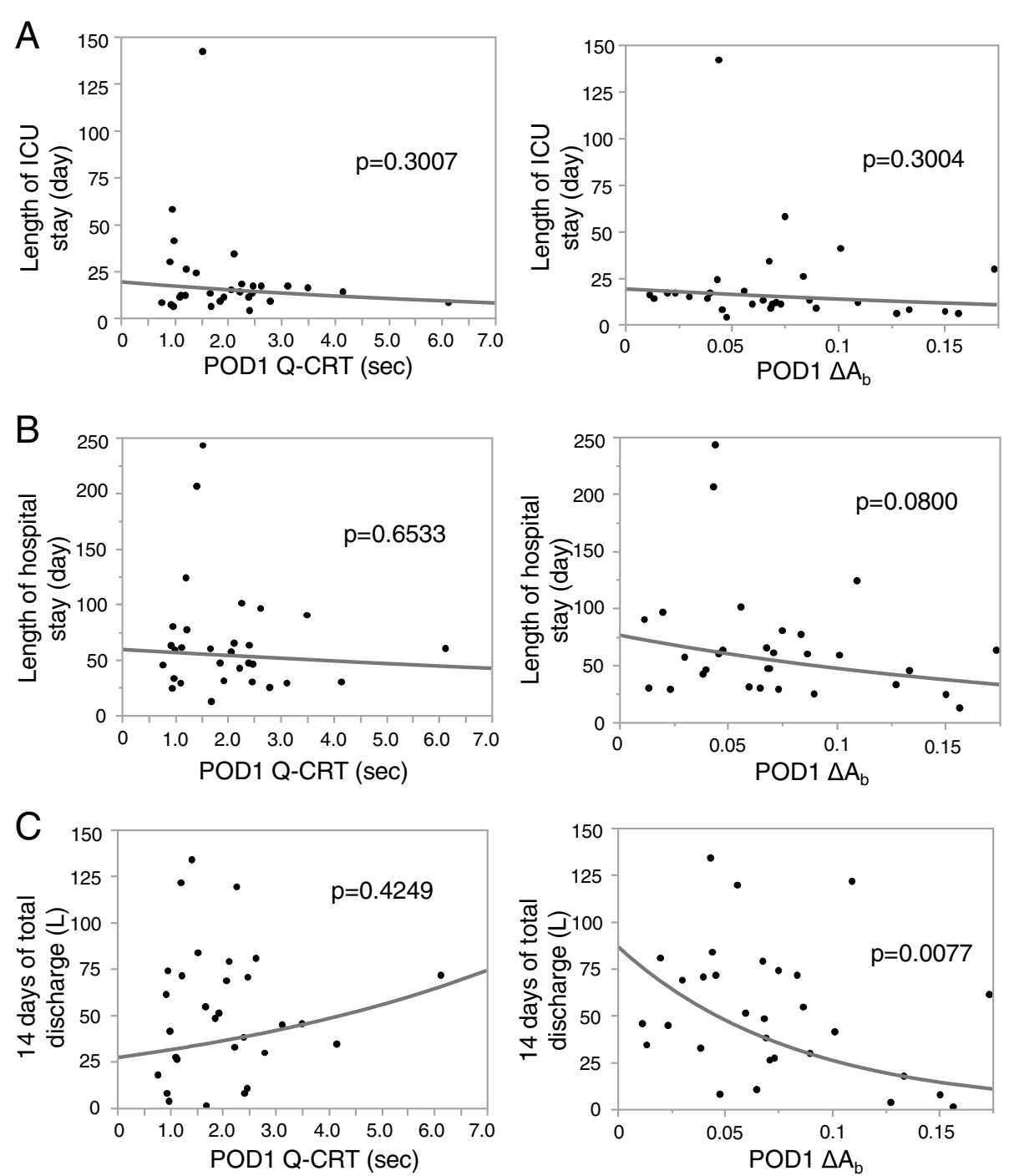

Fig. 3 Correlations of postoperative day 1 values with the outcomes. Correlations of postoperative day $1 \mathrm{Q}-\mathrm{CRT}$ and $\Delta \mathrm{A}_{\mathrm{b}}$ with length of ICU stay (a), postoperative length of hospitalization (b), and total amount of ascites for 14 days after the surgery (c) are shown $(N=30)$. The $p$ value is indicated in each graph

amounts of postoperative ascites [22]. This study also disclosed that patients with a particularly high amount of preoperative ascites tended to have more postoperative ascites. The amount of ascites noted in this study was similar to our previous report [22] and other studies [33,38]. Values and rates reflecting postoperative total bilirubin, acute rejection, and length of hospital stay were significantly higher in patients with massive ascites, although no significant impact of massive ascites on the 5 -year survival rate was observed [22]. In this study, all the patients survived for the observation period of 1 year. Large amounts of diuretics including furosemide, spironolactone, and human atrial natriuretic peptide and albumin administration together with intensive evaluation of intravascular volume are required to control massive ascites.
In patients with a large amount of ascites, close monitoring of the in-out balance and optimal adjustment of fluid administration, which can be achieved in the ICU, is necessary. This may explain the correlation between the length of ICU stay and the amount of ascites present. Although management regarding ICU stay may differ in each country, several Japanese studies reported similar lengths of ICU and hospital stays to this study [39, 40]. It should be noted that other treatments, such as colloid and pressor administration, nutritional support, and antimicrobial agents against infection, should be conducted properly, in addition to a large of fluid resuscitation for perioperative management in liver transplantation. 

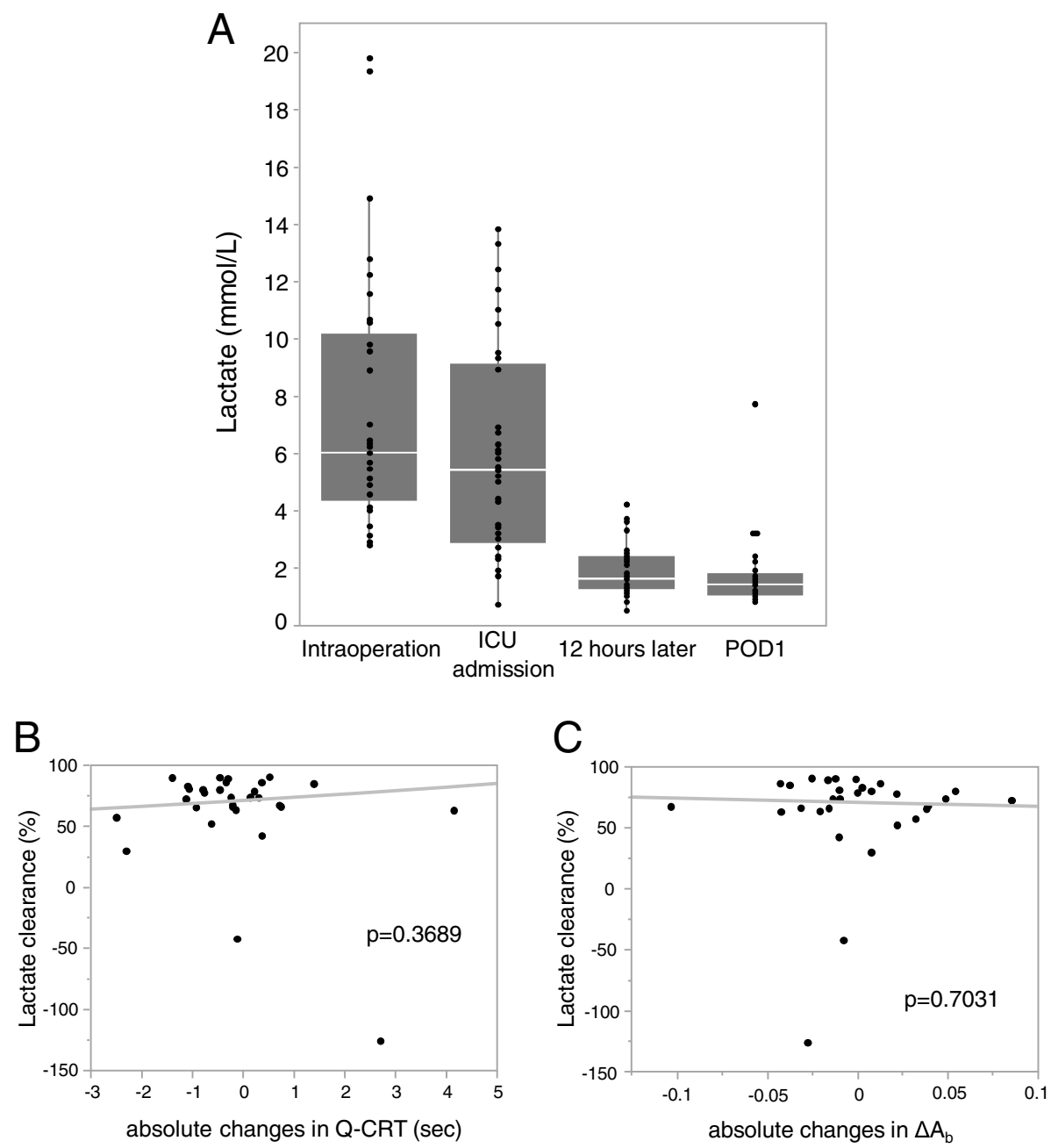

Fig. 4 Serial measurement of lactate clearance. The lactate levels at intraoperative (maximum value), ICU admission, $12 \mathrm{~h}$ later, and POD1 are shown (a). Correlations between absolute changes in Q-CRT (b) and $\Delta \mathrm{A}_{\mathbf{b}}$ (c) from ICU admission to POD1 with lactate clearance $(N=30)$. The $p$ value is indicated in each graph

Table 4 Serial Q-CRT measurements; outcomes related to Q-CRT and $\Delta \mathrm{A}_{\mathrm{b}}$ improvement / worsening

\begin{tabular}{|c|c|c|c|}
\hline & $\begin{array}{l}\text { Q-CRT improvement } \\
(N=19)\end{array}$ & $\begin{array}{l}\text { Q-CRT worsening } \\
(N=11)\end{array}$ & $p$ value \\
\hline Length of ICU stay (day) & $12(9-24)$ & $14(9-18)$ & 0.8126 \\
\hline Length of hospital stay (day) & $60(33-80)$ & $57(30-77)$ & 0.3891 \\
\hline 7 days total discharge $(\mathrm{L})$ & $29.0(14.5-39.6)$ & $20.1(12.3-32.6)$ & 0.3776 \\
\hline \multirow[t]{2}{*}{14 days total discharge $(\mathrm{L})$} & $51.1(26.2-78.9)$ & $41.3(29.6-71.3)$ & 0.5612 \\
\hline & $\Delta A_{b}$ improvement $(N=13)$ & $\Delta A_{b}$ worsening $(N=17)$ & $p$ value \\
\hline Length of ICU stay (day) & $17(10-38)$ & $13(8-17)$ & 0.0978 \\
\hline Length of hospital stay (day) & $60(30-102)$ & $47(32-70)$ & 0.4896 \\
\hline 7 days total discharge $(L)$ & $29.5(19.7-41.1)$ & $18.1(8.1-32.6)$ & 0.0824 \\
\hline 14 days total discharge $(\mathrm{L})$ & $54.4(43.0-81.2)$ & $34.3(14.0-70.9)$ & 0.0753 \\
\hline
\end{tabular}

Summary statistics are reported as medians (lower and upper quartiles). From ICU admission to POD1, those with decreased Q-CRT were defined as improved, and those with increased were defined as worsening. Those with increased delta $A_{b}$ were defined as improved, and those with decreased were defined as worsening 
This study demonstrated that Q-CRT and $\triangle \mathrm{A}_{\mathrm{b}}$ measured immediately after transplantation surgery could identify the patients who would potentially require highly intensive care due to the development of considerable postoperative ascites. Furthermore, it was shown that portal blood flow was associated with Q-CRT and $\Delta \mathrm{A}_{\mathrm{b}}$, and that the closer to normal range was, the less postoperative ascites. Several possible mechanisms may explain this finding. First, Q-CRT and $\Delta \mathrm{A}_{\mathrm{b}}$ can detect a decrease in peripheral perfusion resulting from preoperative liver failure. It is known that a reduction in systemic vascular resistance due to primary arterial vasodilatation in the splanchnic circulation is observed in patients with liver cirrhosis [41, 42]. Activated vasodilator factors such as nitric oxide [43] and endogenous cannabinoids [44] before surgery might exhibit some impact even immediately after transplantation surgery on peripheral tissue perfusion. Second, Q-CRT and $\Delta \mathrm{A}_{\mathrm{b}}$ may indicate the progress of normalization of portal blood flow, and detect the reduced perfusion caused by endotoxin. It is recognized that portal vein blood flow is normalized as the function of the graft liver is restored [45]. A high portal pressure is strongly associated with poor liver transplantation outcomes [46, 47]. A high portal venous pressure reportedly increases gut-related bacteremia in living donor patients with liver transplantations [48] and increases blood endotoxin levels [49, 50]. Several mechanisms such as a vulnerable intestinal barrier [51], changes in the intestinal microbiota [52], and decreased endotoxin clearance in the liver [53] were reported. Hepatic ischemia reperfusion injury negatively affects allograft function following liver transplantation. Although many different involved cell types (sinusoidal endothelial cells, hepatocytes, Kupffer cells, neutrophils, and platelets) and mechanisms (toll-like receptor signaling, micro-RNA expression, production of reactive oxygen species, autophagy, and activation of hypoxiainducible factors) were reported so far [54], it is uncertain whether Q-CRT can detect hepatic ischemia reperfusion injury. It should be noted that many pathological mechanisms, other than ischemia reperfusion injury, are deemed to contribute to poor outcomes for liver transplantation.

Elevated blood lactate levels traditionally were considered a signal of tissue hypoxia. The third international consensus definitions for sepsis and septic shock (Sepsis3) defines septic shock as a clinical construct of sepsis with persisting hypotension requiring vasopressors to maintain a MAP $\geq 65 \mathrm{mmHg}$ and exhibiting a serum lactate level $>2 \mathrm{mmol} / \mathrm{L}$ despite adequate volume resuscitation [55]. Our earlier study found that $\Delta \mathrm{A}_{\mathrm{b}}$ was significantly associated with high lactate levels [12], and we observed a significant correlation between Q-CRT and $\Delta \mathrm{A}_{\mathrm{b}}$ and mean artery pressure in this study, although we did not find any correlation between QCRT and $\triangle \mathrm{A}_{\mathrm{b}}$ with the blood lactate level. The liver plays a major role in systemic lactate clearance, and hyperlactatemia is related to impaired hepatic clearance in advanced cirrhosis [56]. The patients in this study experienced an anhepatic period of approximately $2 \mathrm{~h}$ duration. It assumed that blood lactate and Q-CRT and $\Delta \mathrm{A}_{\mathrm{b}}$ were reflecting different conditions of the patients immediately following liver transplantation surgery; elevated blood lactate was largely influenced by insufficient liver function, and Q-CRT and $\Delta \mathrm{A}_{\mathrm{b}}$ were reflective of peripheral perfusion. The lactate value decreased following perfusion, supporting the lactate clearance function in the liver.

In contrast to Q-CRT and $\triangle \mathrm{A}_{\mathrm{b}}$ values measured immediately after surgery, those measured at POD1 were not significantly associated with the outcomes. Changes from immediately post- surgery to POD1 demonstrated no significant association; however, serial measurements would have provided more information than just single measurements. Several clinical interventions, such as fluid administration, optimizing sedation depth, and mechanical ventilation settings with spontaneous breathing, may affect Q-CRT and $\Delta \mathrm{A}_{\mathrm{b}}$ measurements. It is known that a reliable analysis of respiratory changes in arterial pressure is possible in patients who are sedated and mechanically ventilated with conventional tidal volumes $[57,58]$. Intraoperative measurements may provide a more accurate prediction of postoperative outcomes, as hemodynamics, sedative status, and ventilation are more homogenously managed during general anesthesia. Further assessment during surgery is necessary in order to demonstrate this conjecture.

Several limitations that might affect the results of this study should be acknowledged. First, this study was performed at a single ICU, and the number of patients was relatively small. Second, no evaluation study of Q-CRT and $\Delta \mathrm{A}_{\mathrm{b}}$ using the widely accepted gold standard of hemodynamic assessment such as cardiac output, oxygen delivery $\left(\mathrm{DO}_{2}\right)$ and oxygen consumption $\left(\mathrm{VO}_{2}\right)$ has been conducted to date. Third, Q-CRT and $\triangle \mathrm{A}_{\mathrm{b}}$ measurements were recorded only at ICU admission and POD1. As discussed above, adding intraoperative and preoperative measurements may have provided more useful information. Presumably, the hypoperfusion evaluated by Q-CRT and $\triangle \mathrm{A}_{\mathrm{b}}$ measurement reflects hypoperfusion of the grafted liver, and hypoperfusion to the liver might have induced massive ascites. Further investigation is necessary to clarify the pathophysiological mechanism causing massive ascites after liver transplantation. Finally, an earlier study reported CRT longer than $3 \mathrm{~s}$ was not predictive of mortality in patients complicated with malarial anemia [59], although no patients manifested severe anemia in our-study. 


\section{Conclusion}

This prospective observational study found that Q-CRT with a pulse oximeter was significantly associated with postoperative outcomes in patients receiving liver transplantations. Q-CRT may be relevant as a new noninvasive monitoring tool for patients treated in ICUs upon validation by several different ICU patient cohorts such as post-cardiac surgery, heart failure, and patients with multiple organ failures.

\section{Supplementary information}

Supplementary information accompanies this paper at https://doi.org/10. 1186/s12871-020-01171-y.

Additional file 1. Preoperative baseline characteristics, graft conditions, surgery-related factors, clinical parameters at ICU admission after surgery. Additional file $\mathbf{2}$ Correlations of $\mathrm{Q}-\mathrm{CRT}$ and $\Delta \mathrm{A}_{\mathrm{b}}$ with clinical parameters. Correlations of $\mathrm{Q}-\mathrm{CRT}$ and $\triangle \mathrm{A}_{b}$ with heart rate $(H R)(\mathrm{A})$, central venous pressure (CVP) (B), blood lactate $(C)$, hemoglobin $(\mathrm{Hb})(\mathrm{D})$, hepatic arterial velocity $(H A)(E)$, hepatic venous velocity $(H V)(F)$ are shown Measures observed at similar time points $(N=33)$. The $p$ value is indicated in each graph.

Additional file $\mathbf{3}$ Correlations of liver blood flow with the outcomes. Correlation with the total amount of discharge for 7 days and 14 days post-surgery with PV (A) and HA (B) and HV $(C)$ are shown $(N=33)$. The $p$ value is indicated in each graph.

Additional file 4 Postoperative ascites in relation to preoperative ascites. Postoperative total amounts of discharge at POD7 (A) and POD14 (B) in the none (no ascites, $N=20)$, the non-massive $(1-999 \mathrm{ml}, N=4)$, and the massive (more than $1000 \mathrm{ml}, N=9$ ) groups were shown. The $p$ value is in dicated in each graph.

Additional file 5. Comparison of the non-massive ascites group with the massive ascites group.

Additional file 6 . The cut-off values of $\mathrm{Q}-\mathrm{CRT}$ and $\Delta \mathrm{A}_{\mathrm{b}}$ for each outcome.

Additional file $\mathbf{7}$ Serial measurements of quantitative capillary refill time and $\Delta A_{b}$. Correlations between the absolute changes in Q-CRT and $\Delta A_{b}$ from ICU admission to POD1 with ICU stay (A), postoperative length of hospitalization (B), and total amount of ascites for 14 days after the surgery $(C)$ are shown $(N=30)$. The $p$ value is indicated in each graph.

\section{Abbreviations}

AUC: area under the curve; $\mathrm{Cl}$ : confidence interval; CRT: capillary refill time; CVP: central venous pressure; ED: emergency department; HA: hepatic artery; $\mathrm{Hb}$ : hemoglobin; HR: heart rate; HV: hepatic vein; ICU: intensive care unit; MAP: mean arterial pressure; MELD: model for end-stage liver disease: POD: postoperative day; PV: portal vein; PT-INR: prothrombin time international normalized ratio; Q-CRT: quantitative capillary refill time; ROC: receiver operating characteristic curve; $\Delta A_{b}$ : delta $A_{b}$

\section{Acknowledgements}

The authors wish to thank Hideaki Hirahara and Naoki Kobayashi (Nihon Kohden Corporation, Tokyo, Japan) for their support with data analysis. We also thank Dr. Harufumi Maki for his advice on data interpretation in this study.

\section{Authors' contributions}

MY designed the study, performed informed consent to participants and the measurement of data, analyzed the data, interpreted the findings, prepared the figures and tables, and drafted the manuscript. KD contributed to the design of the study, analyzed the data, interpreted the findings, and revised the manuscript. $\mathrm{NH}$ and TA contributed to the analyzed the data and interpreted the findings. NA interpreted the findings and revised the manuscript. JK and $\mathrm{KH}$ interpreted the findings. NM had the initial idea and supervised the study, interpreted the findings. All authors read and approved the final manuscript.

\section{Funding}

There was no funding source for this work.

\section{Availability of data and materials}

The datasets used and/or analyzed during the current study available from the corresponding author on reasonable request.

Ethics approval and consent to participate

The study was approved by the institutional review board of the University of Tokyo (reference number: 11773). Informed consent was obtained from each participant by written.

\section{Consent for publication}

Not applicable.

\section{Competing interests}

The authors declare that they have no competing interests.

\section{Author details}

'Department of Acute Medicine, The University of Tokyo, 7-3-1 Hongo, Bunkyo-ku, Tokyo 113-0033, Japan. ${ }^{2}$ Hepato-Biliary-Pancreatic Surgery Division, Artificial Organ and Transplantation Division, Department of Surgery, The University of Tokyo, Tokyo, Japan.

Received: 17 June 2020 Accepted: 22 September 2020

Published online: 29 September 2020

\section{References}

1. Gottrup F. Physiology and measurement of tissue perfusion. Ann Chir Gynaecol. 1994;83(3):183-9.

2. Livingston $\mathrm{DH}$, Deitch EA. Multiple organ failure: a common problem in surgical intensive care unit patients. Ann Med. 1995;27(1):13-20.

3. Kirov MY, Kuzkov W, Molnar Z. Perioperative haemodynamic therapy. Curr Opin Crit Care. 2010;16(4):384-92

4. De Backer D, Ospina-Tascon G, Salgado D, Favory R, Creteur J, Vincent JL. Monitoring the microcirculation in the critically ill patient: current methods and future approaches. Intensive Care Med. 2010;36(11):1813-25.

5. Koh $I H$, Menchaca-Diaz JL, Koh TH, Souza RL, Shu CM, Rogerio VE, Liberatore AM. Microcirculatory evaluation in sepsis: a difficult task. Shock. 2010; 34(Suppl 1):27-33.

6. Benson M, Koenig KL, Schultz CH. Disaster triage: START, then SAVE--a new method of dynamic triage for victims of a catastrophic earthquake. Prehosp Disaster Med. 1996;11(2):117-24.

7. Beecher HK, Simeone FA, et al. The internal state of the severely wounded man on entry to the most forward hospital. Surgery. 1947;22(4):672-711.

8. Hernandez G, Ospina-Tascon GA, Damiani LP, Estenssoro E, Dubin A Hurtado J, Friedman G, Castro R, Alegria L, Teboul JL, et al. Effect of a resuscitation strategy targeting peripheral perfusion status vs serum lactate levels on 28-day mortality among patients with septic shock: the ANDROMEDA-SHOCK randomized clinical trial. Jama. 2019;321(7):654-64

9. Schriger DL, Baraff L. Defining normal capillary refill: variation with age, sex, and temperature. Ann Emerg Med. 1988;17(9):932-5.

10. Schriger DL, Baraff LJ. Capillary refill--is it a useful predictor of hypovolemic states? Ann Emerg Med. 1991;20(6):601-5.

11. Morimura N, Takahashi K, Doi T, Ohnuki T, Sakamoto T, Uchida Y, Takahashi $\mathrm{H}$, Fujita T, Ikeda H. A pilot study of quantitative capillary refill time to identify high blood lactate levels in critically ill patients. Emerg Med J. 2015; 32(6):444-8

12. Oi Y, Sato K, Nogaki A, Shinohara M, Matsumoto J, Abe T, Morimura N. Association between venous blood lactate levels and differences in quantitative capillary refill time. Acute Med Surg. 2018;5(4):321-8.

13. Yoo S, Jang EJ, Yi NJ, Kim GH, Kim DH, Lee H, Jung CW, Ryu HG. Effect of institutional case volume on in-hospital mortality after living donor liver transplantation: analysis of 7073 cases between 2007 and 2016 in Korea. Transplantation. 2019;103(5):952-8.

14. Umeshita K, Eguchi S, Egawa H, Haga H, Kasahara M, Kokudo N, Sakisaka S, Takada Y, Tanaka E, Eguchi H, et al. Liver transplantation in Japan: registry 
by the Japanese liver transplantation society. Hepatol Res. 2019;49(9):96480 .

15. Kwong A, Kim WR, Lake JR, Smith JM, Schladt DP, Skeans MA, Noreen SM, Foutz J, Miller E, Snyder JJ, et al. OPTN/SRTR 2018 Annual Data Report: Liver. Am J Transplant. 2020;20(Suppl s1):193-299.

16. Garcia-Alvarez M, Marik P, Bellomo R. Sepsis-associated hyperlactatemia. Crit Care. 2014;18(5):503.

17. Hernandez G, Bellomo R, Bakker J. The ten pitfalls of lactate clearance in sepsis. Intensive Care Med. 2019;45(1):82-5.

18. Perilli V, Aceto P, Sacco T, Ciocchetti P, Papanice D, Lai C, Sollazzi L. Usefulness of postreperfusion lactate clearance for predicting early graft recovery in liver transplant patients: a single center study. Minerva Anestesiol. 2018;84(10):1142-9.

19. Kim DG, Lee JY, Jung YB, Song SH, Lee JG, Han DH, Joo DJ, Ju MK, Choi GH, Choi JS, et al. Clinical significance of lactate clearance for the development of early allograft dysfunction and short-term prognosis in deceased donor liver transplantation. Clin Transplant. 2017;31(12):e13136.

20. Svensson KL, Persson H, Henriksson BA, Karlberg I, Sonander H, Lundholm K, Stenqvist $\mathrm{O}$, Scherstén $\mathrm{T}$. Whole body gas exchange: amino acid and lactate clearance as indicators of initial and early allograft viability in liver transplantation. Surgery. 1989;105(4):472-80.

21. Olthoff KM, Kulik L, Samstein B, Kaminski M, Abecassis M, Emond J, Shaked A, Christie JD. Validation of a current definition of early allograft dysfunction in liver transplant recipients and analysis of risk factors. Liver Transpl. 2010; 16(8):943-9.

22. Ito D, Akamatsu N, Togashi J, Kaneko J, Arita J, Hasegawa K, Sakamoto Y, Kokudo N. Behavior and clinical impact of ascites after living donor liver transplantation: risk factors associated with massive ascites. J Hepatobiliary Pancreat Sci. 2016;23(11):688-96.

23. Soejima Y, Taketomi A, Yoshizumi T, Uchiyama H, Harada N, ljichi H, Yonemura Y, Shimada M, Maehara Y. Feasibility of left lobe living donor liver transplantation between adults: an 8-year, single-center experience of 107 cases. Am J Transplant. 2006;6(5 Pt 1):1004-11.

24. Hill MJ, Hughes M, Jie T, Cohen M, Lake J, Payne WD, Humar A. Graft weight/recipient weight ratio: how well does it predict outcome after partial liver transplants? Liver Transpl. 2009:15(9):1056-62.

25. John RT, Henricson J, Anderson CD, Wilhelms DB. Man versus machine: comparison of naked-eye estimation and quantified capillary refill. Emerg Med J. 2019;36(8):465-71

26. Shinozaki K, Saeki K, Jacobson LS, Falotico JM, Li T, Hirahara H, Horie K, Kobayashi N, Weisner S, Lampe JW, et al. Evaluation of accuracy of capillary refill index with pneumatic fingertip compression. J Clin Monit Comput. 2020. https://doi.org/10.1007/s10877-019-00454-1.

27. Kawaguchi R, Nakada TA, Oshima T, Shinozaki M, Nakaguchi T, Haneishi H, Oda S. Optimal pressing strength and time for capillary refilling time. Crit Care. 2019;23:4.

28. Shinozaki M, Nakada TA, Kawaguchi R, Yoshimura Y, Nakaguchi T, Haneishi $\mathrm{H}$, Oda S. Feedback function for capillary refilling time measurement device. Crit Care. 2019;23:295.

29. Shinozaki K, Jacobson LS, Saeki K, Kobayashi N, Weisner S, Falotico JM, Li T, Kim J, Lampe JW, Becker LB. Does training level affect the accuracy of visual assessment of capillary refill time? Crit Care. 2019;23:157.

30. Oi Y, Morimura N, Shirasawa A, Honzawa H, Oyama Y, Niida S, Abe T, Imak S, Takeuchi I. Quantitative capillary refill time predicts sepsis in patients with suspected infection in the emergency department: an observational study. J Intensive Care. 2019;7:29.

31. Shinozaki K, Jacobson LS, Saeki K, Hirahara H, Kobayashi N, Weisner S, Falotico JM, Li T, Kim J, Becker LB. Comparison of point-of-care peripheral perfusion assessment using pulse oximetry sensor with manual capillary refill time: clinical pilot study in the emergency department. J Intensive Care. 2019;7:52.

32. Shirouzu Y, Ohya Y, Suda H, Asonuma K, Inomata Y. Massive ascites after living donor liver transplantation with a right lobe graft larger than $0.8 \%$ of the recipient's body weight. Clin Transpl. 2010;24(4):520-7.

33. Iwaki K, Yagi S, Morita S, Hamaguchi Y, Masano Y, Yamamoto G, Ogawa E, Nagai K, Kamo N, Hata K, et al. Impact of graft quality and fluid overload on postoperative massive ascites after living donor liver transplantation. Transplant Proc. 2019;51(6):1779-84.

34. Gotthardt DN, Weiss KH, Rathenberg V, Schemmer P, Stremmel W, Sauer P. Persistent ascites after liver transplantation: etiology, treatment and impact on survival. Ann Transplant. 2013;18:378-83.
35. Li C, Lu Q, Luo J, Zhang Z. Independent risk factors for massive ascites after living donor liver transplantation in adults. Transplant Proc. 2014;46(3):8837.

36. Millikan WJ Jr, Henderson JM, Stewart MT, Warren WD, Marsh JW, Galloway JR, Jennings H, Kawasaki S, Dodson TF, Perlino CA, et al. Change in hepatic function, hemodynamics, and morphology after liver transplant. Physiological effect of therapy. Ann Surg. 1989;209(5):513-25.

37. Yi NJ, Suh KS, Cho YB, Lee HW, Cho EH, Cho JY, Shin WY, Kim J, Lee KU. The right small-for-size graft results in better outcomes than the left small-forsize graft in adult-to-adult living donor liver transplantation. World J Surg. 2008;32(8):1722-30.

38. Uemura T, Wada S, Kaido T, Mori A, Ogura Y, Yagi S, Fujimoto Y, Ogawa K, Hata K, Yoshizawa A, et al. How far can we lower graft-to-recipient weight ratio for living donor liver transplantation under modulation of portal venous pressure? Surgery. 2016;159(6):1623-30.

39. Akamatsu N, Sugawara Y, Kokudo N, Eguchi S, Fujiwara T, Ohdan H, Nagano $\mathrm{H}$, Taketomi A, Kitagawa $Y$, Shimada $M$, et al. Outcomes of living donor liver transplantation for hepatitis $C$ virus-positive recipients in Japan: results of a nationwide survey. Transpl Int. 2014;27(8):767-74.

40. Shiba H, Wakiyama S, Futagawa Y, lida T, Matsumoto M, Haruki K, Ishida Y, Misawa T, Yanaga K. Assessment of graft selection criteria in living-donor liver transplantation: the Jikei experience. Int Surg. 2015;100(7-8):1229-32.

41. Arroyo V, Gines P, Gerbes AL, Dudley FJ, Gentilini P, Laffi G, Reynolds TB, Ring-Larsen $\mathrm{H}$, Scholmerich J. Definition and diagnostic criteria of refractory ascites and hepatorenal syndrome in cirrhosis. International Ascites Club. Hepatology. 1996;23(1):164-76.

42. Gines P, Schrier RW. Renal failure in cirrhosis. N Engl J Med. 2009;361(13): 1279-90.

43. Martin PY, Gines $P$, Schrier RW. Nitric oxide as a mediator of hemodynamic abnormalities and sodium and water retention in cirrhosis. N Engl J Med. 1998;339(8):533-41.

44. Ros J, Claria J, To-Figueras J, Planaguma A, Cejudo-Martin P, FernandezVaro G, Martin-Ruiz R, Arroyo V, Rivera F, Rodes J, et al. Endogenous cannabinoids: a new system involved in the homeostasis of arterial pressure in experimental cirrhosis in the rat. Gastroenterology. 2002; 122(1):85-93.

45. Bolognesi M, Sacerdoti D, Bombonato G, Merkel C, Sartori G, Merenda R, Nava V, Angeli P, Feltracco P, Gatta A. Change in portal flow after liver transplantation: effect on hepatic arterial resistance indices and role of spleen size. Hepatology. 2002;35(3):601-8.

46. Ito T, Kiuchi T, Yamamoto H, Oike F, Ogura Y, Fujimoto Y, Hirohashi K, Tanaka AK. Changes in portal venous pressure in the early phase after living donor liver transplantation: pathogenesis and clinical implications. Transplantation. 2003;75(8):1313-7.

47. Gyoten K, Mizuno S, Kato H, Murata Y, Tanemura A, Azumi Y, Kuriyama N, Kishiwada M, Usui M, Sakurai H, et al. A novel predictor of Posttransplant portal hypertension in adult-to-adult living donor liver transplantation: increased estimated spleen/graft volume ratio. Transplantation. 2016; 100(10):2138-45.

48. Yao S, Yagi S, Uozumi R, lida T, Nagao M, Okamura Y, Anazawa T, Okajima $\mathrm{H}$, Kaido $\mathrm{T}$, Uemoto $\mathrm{S}$. A high portal venous pressure gradient increases gutrelated bacteremia and consequent early mortality after living donor liver transplantation. Transplantation. 2018;102(4):623-31.

49. Okada N, Sanada Y, Urahashi T, Ihara Y, Yamada N, Hirata Y, Katano T, Otomo S, Ushijima K, Mizuta K. Endotoxin metabolism reflects hepatic functional Reserve in end-Stage Liver Disease. Transplant Proc. 2018;50(5): 1360-4.

50. DeGasperi A, DeCian W, Vaiani F, Corti A, Sabbadini D, Pannacciulli E, Amici O, Mazza E, Cristalli A, Prosperi M, et al. Endotoxemia following liver transplantation in humans. Transplant Proc. 1994;26(6):3664-5.

51. Wiest R, Lawson M, Geuking M. Pathological bacterial translocation in liver cirrhosis. J Hepatol. 2014;60(1):197-209.

52. Giannelli V, Di Gregorio V, lebba V, Giusto M, Schippa S, Merli M, Thalheimer U. Microbiota and the gut-liver axis: bacterial translocation, inflammation and infection in cirrhosis. World J Gastroenterol. 2014;20(45):16795-810.

53. Sanada Y, Mizuta K, Urahashi T, Ihara Y, Wakiya T, Okada N, Yamada N, Ushijima K, Otomo S, Sakamoto K, et al. Impact of hepatic clearance of endotoxin using endotoxin activity assay. Hepatol Int. 2012;6(4):778-82.

54. Dar WA, Sullivan E, Bynon JS, Eltzschig H, Ju C. Ischaemia reperfusion injury in liver transplantation: cellular and molecular mechanisms. Liver Int. 2019; 39(5):788-801. 
55. Singer M, Deutschman CS, Seymour CW, Shankar-Hari M, Annane D, Bauer M, Bellomo R, Bernard GR, Chiche JD, Coopersmith CM, et al. The third international consensus definitions for Sepsis and septic shock (Sepsis-3). Jama. 2016;315(8):801-10.

56. Jeppesen JB, Mortensen C, Bendtsen F, Moller S. Lactate metabolism in chronic liver disease. Scand J Clin Lab Invest. 2013;73(4):293-9.

57. Michard F. Changes in arterial pressure during mechanical ventilation. Anesthesiology. 2005;103(2):419-28.

58. Perner A, Faber T. Stroke volume variation does not predict fluid responsiveness in patients with septic shock on pressure support ventilation. Acta Anaesthesiol Scand. 2006;50(9):1068-73.

59. Pamba A, Maitland K. Capillary refill: prognostic value in Kenyan children. Arch Dis Child. 2004;89(10):950-5.

\section{Publisher's Note}

Springer Nature remains neutral with regard to jurisdictional claims in published maps and institutional affiliations.

- fast, convenient online submission

- thorough peer review by experienced researchers in your field

- rapid publication on acceptance

- support for research data, including large and complex data types

- gold Open Access which fosters wider collaboration and increased citations

- maximum visibility for your research: over $100 \mathrm{M}$ website views per year

At $\mathrm{BMC}$, research is always in progress.

Learn more biomedcentral.com/submissions 